by general practitioner obstetricians has dwindled to the point where it represents a largely voluntary activity by a diminishing number of masochistic enthusiasts. The number of general practitioners holding clinical assistant or hospital practitioner appointments in obstetrics is minimal. The item of service payment for providing intrapartum care, $£ 33.35$, has been overtaken by that for inserting an intrauterine contraceptive device, $£ 41.25$, and recently by that for doing a single night visit, $£ 43.35$. It is totally unrealistic to expect a highly professional service to be provided in this way in the 1990s and beyond.

Intrapartum care must be recognised as the most demanding aspect of general practice. Of all clinical activities it is the most easily measured and audited, and there is no reason why it cannot meet the highest standards. The Royal College of Obstetricians and Gynaecologists awards more than 1000 diplomas annually, and an appreciable minority of doctors who have received obstetric training could be recruited to the intrapartum service, if encouraged. The nature of the work, however, requires that some limitations must be placed on those doctors' other commitments in general practice. This problem has not yet been addressed in the new contract by our negotiators, by the Royal College of Obstetricians and Gynaecologists, or by the Royal College of General Practitioners.

The time for wringing of hands and half measures is surely over. Clearly defined standards, and incentives to ensure that they are met, are now needed: anything less will ensure the demise of intrapartum care by general practitioners in the next decade.

A J M CAVENAGH

Brecon LD3 7AA

1 Bryce FC, Clayton JK, Rand RJ, Beck I, Farquharson DJM, Jones SE. General practitioner obstetrics in Bradford. Br.Med f 1990;300:725-7. (17 March.)

**T This correspondence is now closed. - ED, $B M \mathcal{F}$.

\section{Perimenopausal women's views on hormone replacement therapy}

SIR,-Doctors were quick to criticise Kenneth Clarke's claim that 850 general practices had "expressed an interest" in budget holding. Must we not apply a similar logic to the study by Cambridge general practitioners Drs Juliet Draper and Martin Roland on hormone replacement therapy? Mr Clarke's "sample" filled in a form inviting them, under no obligation, to discuss budget holding further; many simply wanted to receive more information. The Cambridge practice population "expressed an interest" in taking hormone replacement therapy in the context of receiving two personally addressed questionnaires from their general practitioner and in some cases a telephone call as well. In fact they were asked whether they would be interested in taking hormone replacement therapy to prevent osteoporosis "if they were recommended to do so." That all but the $17 \%$ who were "definitely interested" would presumably be prepared to resist a medical "recommendation" is interesting; it is quite remarkable that they replied in this sceptical way to a letter that presented the menopause in a totally negative light and detailed the horrors of osteoporosis without explaining the time taken for the problems to develop ("some patients might have understood from the letter that the development of osteoporosis occurs at the time of the menopause").

Furthermore, the authors concede that the period of treatment required to prevent fractures occurring is unknown, but their letter to patients states that taking hormone treatment for five years can help to prevent osteoporosis. Surely if we want to discover perimenopausal women's views on taking hormone replacement therapy - to prevent osteoporosis or for any other purpose-we have a duty at least to provide them with information that we believe to be accurate.

The financial implications for drug companies of the enormous potential market for hormone replacement therapy mean that it is incumbent on doctors to protect the varied interests of individual patients. A blanket policy of encouraging (or discouraging) the use of hormone replacement therapy will not address these specific needs. The resource implications for the NHS of reaching a reasoned and negotiated decision with each woman would, however, clearly be enormous, in terms of both the drug budget and time spent with the women. What a pity that the current changes in the NHS, with the increase in administrative work and longer general practitioner list sizes favoured by the shift towards capitation, are unlikely to make more time available for such work.

Oxford OX4 IPY

MIRANDA MINDLIN

1 Draper J, Roland $M$. Perimenopausal women's views on taking hormone replacement therapy to prevent osteoporosis. BrMed F 1990;300:786-8. (24 March.)

2 Anonymous. Consensus development conference: prophylaxis and treatment of osteoporosis. Br Med I 1987;295:914-5.

SIR, - Given the current high level of interest in hormone replacement therapy for perimenopausal and postmenopausal women we feel obliged to take issue with the theoretical nature of the observations of Drs Juliet Draper and Martin Roland.' These show that three quarters of the women whom they surveyed expressed an interest in taking hormone replacement therapy. Though we do not dispute this figure, we question its importance in terms of uptake among these women if they were actually given the opportunity to receive the treatment. Do the authors really believe that expressing an interest in the treatment on a questionnaire is indicative of a commitment to take hormone replacement therapy in the future?

A study of acceptability of the treatment to postmenopausal women has been carried out in Nottingham. In all, 100 women between the ages of 50 and 70 who had sustained a distal radial fracture were offered hormone replacement therapy to protect them from osteoporosis. These women were counselled comprehensively regarding both the benefits and possible side effects of the treatment. The results differed considerably from those of Drs Draper and Roland.

Initially, 66 of the women expressed an interest in hormone replacement therapy. When offered specific appointments for gynaecological screening before receiving the treatment 30 women changed their minds, giving an initial uptake of the treatment of only $36 \%$. The younger women in the study showed more willingness to take hormone replacement therapy and were less bothered by the continuation of their menstrual periods than those who had not menstruated for some time. We therefore appreciate that the difference in age groups between the two studies must have some bearing on our results compared with those of Drs Draper and Roland, but we believe that the large discrepancy is due ultimately to the difference between the theory and the practice of hormone replacement therapy. C A ELLIOTT M B A MACPHERSON

Department of Orthopaedic and Accident Surgery,

University Hospital

Queen's Medical Centre,

Nottingham NG7 2UH

1 Draper J, Roland M. Perimenopausal women's views on taking hormone replacement therapy to prevent osteoporosis. Br Med F 1990;300:786-8. (24 March.)

\section{Benefits of thrombolysis}

SIR,-The extensive correspondence' on the dangers of thrombolysis contained many valuable comments but did not emphasise sufficiently the generally much greater dangers of failing to give thrombolysis to patients with suspected acute myocardial infarction.

The most extensively tested and least expensive thrombolytic agent is streptokinase, and no other has been shown to produce a reduction in mortality better than that produced by an intravenous infusion of 1.5 million units. Life threatening side effects of this regimen have been described in the reports of randomised trials such as the second international study of infarct survival (ISIS-2). ${ }^{2}$ Yet ISIS-2 showed benefit for a wide range of patients, including many who did not have definite ST segment elevation on electrocardiography and those who developed pain many hours before treatment. If aspirin $160 \mathrm{mg}$ a day was also added the benefit was twice as large: 343 deaths $(8.0 \%)$ with streptokinase and aspirin as against 568 deaths $(13 \cdot 2 \%)$ with neither. This reduction in the odds of death applied similarly to many types of patient: old and young, hypertensive and hypotensive, men and women, those with first and subsequent myocardial infarction, those with ST segment elevation on electrocardiography and those without, those who were treated promptly and those who were not. Reduction in mortality was accompanied by a net reduction in strokes.

The best interests of patients require doctors to be guided not only by the possibility of the incidence of side effects but more by the expected net gain for particular patients having thrombolysis and aspirin. This gain is probably substantial in a wide range of circumstances.

RICHARD PETO

Clinical Trial Service Unit RORY COLLINS

and ICRF Studies Unit,
and

Radcliffe Infirmary,

Oxford OX2 6WE

\section{Correspondence. Dangers of thrombolysis. Br Med $\mathcal{f}$ 1990;300: 810-11. (24 March \\ 2 ISIS-2 (Second International Study of Infarct Survival) Collabo- rative Group. Randomised trial of intravenous streptokinase oral aspirin, both, or neither among 17187 cases of suspected myocardial infarction (ISIS-2.) Lancet 1988;ii:349-60. \\ Thrombolysis and the general practitioner}

SIR, - While there may be debate about the use of thrombolytic treatment by general practitioners, ${ }^{1 / 2}$ there is general agreement that thrombolysis can be life saving in acute myocardial infarction. Professor P C Rubin comments that patients with suspected myocardial infarction should be admitted to hospital'; and, given the widespread use of thrombolytic treatment, the entire question of whether patients with acute myocardial infarction should be treated at home or in hospital merits reappraisal.

We surveyed 69 principals in general practice in west Fife to determine their views regarding home or hospital care of patients with acute myocardial infarction. ${ }^{3}$ Most (67) were aware that thrombolytic treatment could be beneficial in the first six hours after acute myocardial infarction and they would request hospital admission for most patients aged up to 71 within this time. Only 11 doctors, however, thought that treatment could be effective beyond six hours and 32 chose home care within 13 hours of the onset of symptoms for a hypothetical patient aged 66 .

Studies performed before the introduction of thrombolytic treatment reported that general practitioners were more likely to recommend home care for elderly patients. ${ }^{+}$In our survey only 23 doctors would request hospital admission for 
patients aged 80 or more. Although there is uncertainty about the exact criteria for thrombolytic treatment, the second international study of infarct survival (ISIS-2) showed some benefit for patients treated up to 24 hours after the onset of symptoms, and age was no contraindication to treatment.

Our results suggest that while most general practitioners are aware of the potential benefits of thrombolysis, they may be denying the treatment to considerable numbers of patients whom they do not admit to hospital. We suggest that, although domiciliary thrombolytic treatment might be appropriate in certain circumstances, it is more important that general practitioners modify their referral patterns so that thrombolysis is available to all patients within 24 hours of the onset of symptoms.

ALASTAIR C H PELL PAULINE C STUART

Royal Infirmary,

Edinburgh EH3 9YW

MICHAEL J STEWART

Milesbank Hospital DAVID M FRASER

Rumblingwell

Dunfermline KY12 9NR

1 Fox KAA. Thrombolysis and the general practitioner. Br.Med $\mathcal{J}$ 1990;300:867-8. (31 March.)

2 Wilcox RG. Thrombolysis and the general practitioner. Br Med $\mathcal{F}$ 1990;300:869-70. (31 March.)

3 Pell ACH, Stuart PC, Stewart MJ, Fraser DM. Home or hospital care of acute myocardial infarction in the thrombolytic era? A survey of general practitioners' attitudes. Foumal of the Royal College of General Practitioners (in press)

4 Mcllmoyle EL, Kerr MM, Mathewson ZM, Elwood JH, Evans AE. Myocardial infarction: hospital and home management in Northern Ireland Fournal of the Roval College of Gieneral Practitioners 1985;35:280-3.

5 ISIS-2 (second international study of infarct survival) Collaborative Group. Randomised trial of intravenous streptokinase, oral aspirin, both, or neither among 17187 cases of suspected acute myocardial infarction: ISIS-2. Lancet 1988;ii:349-60.

\section{Medical problems of adults who were sexually abused in childhood}

SIR,-Claims that specific types of adult psychopathology are the result of sexual abuse in child hood have become fashionable in psychiatry. The paper by Dr R P Arnold and colleagues is an example. ${ }^{1}$ But their claim for an association between childhood sexual abuse and adult somatisation is seriously flawed in two respects.

Firstly, the patients were ascertained by asking three consultant adult psychiatrists to report on any patients seen during the previous 12 months who had experienced full sexual intercourse under the age of 16 with an adult. This introduced a selection bias, which is not commented on. Secondly, there was no control group.

We have studied this problem from a different perspective and found no evidence to support a specific association between childhood sexua abuse and long term somatisation in adult life. We compared 25 patients with a somatisation disorder (according to DSM-R criteria ${ }^{2}$ ) with 20 age and sex matched controls (these were consecutive patients referred to our outpatient unit with anxiety or depression). Both groups were interviewed with the diagnostic interview schedule ${ }^{3}$ and also underwent a semistructured interview that covered sexual and physical abuse in childhood. We not only collected the general practitioner and hospital notes of the patients with a somatisation disorder but also continued to manage them on an individual basis in a designated clinic, in some cases for as long as 12 years. We will confine our comments to two issues: rates of reported sexual abuse and management strategies.

We found that childhood sexual abuse was reported as frequently by the patients with a somatisation disorder as by the controls $(20 \% v$ $17 \%$ of subjects). Although we have carried out only a preliminary analysis of our data, the most important difference between the two groups (apart from the expected excess of unnecessary surgery and iatrogenic illness in the patient group) was in the rates of illness in the subjects' parents. Over half of the patients with a somatisation disorder reported that during their formative years (0-16 years) one or both parents were severely handicapped by illness. By contrast, only one of the controls was exposed to serious physical illness in a parent. Furthermore, physical illness during childhood was also more common in the patient group.

Our findings suggest that long term somatisation arises in a range of adverse family contexts: these include exposure to physical illness in parents as well as neglect or scapegoating by parents and experiences in foster homes. It seems more likely that several early adverse factors contribute in a complex way to the development of somatisation in adult life and that a unitary explanation-sexual abuse - is a gross oversimplification.

Finally, Dr Arnold and colleagues are correct in stating that such patients present a challenge to psychiatry. We have not, however, found the resistance against psychiatric intervention reported by these authors. Patients with a somatisation disorder can be engaged in psychological treatment but not by "direct confrontation about symptoms that cannot be assessed objectively." Techniques for engaging these patients have been described, ${ }^{+5}$ and a study showing the efficacy of such intervention has been reported. ${ }^{6}$ The cornerstone of proper management is collaboration between the psychiatrist and both general practitioner and hospital specialists. Collaboration with hospital specialists is more likely to occur when departments of psychiatry are located within the district general hospital and not geographically separate from it.

C BASS

Academic Department of Psychological Medicine

King's College Hospital,

London SE5 9RS

1 Arnold RP, Rodgers D, Cooke DAG. Medical problems of adults who were sexually abused in childhood. Br Med 7 1990;300: 705-8. (17 March)

2 American Psychiatric Association. Diagnostic and statistical manual of mental diseases. 3rd ed. Washington, DC: APA, 1987.

3 Robins LN, Helzer JE, Ratcliff KS, Seyfried W. Validity of the diagnostic interview schedule, version II: DSM III diagnoses. diagnostic interview schedule,
Pswchol Med 1982;12:855-70.

+ Bass C, Murphy M. Somatization disorder. Critique of the concept and suggestions for future research. In: Bass $C$, ed. Somatization: physical symptoms and psychological illness. Oxford: Blackwell Scientific (in press).

5 Smith GR. Somatization disorder in the medical setting. (National Institute of Medical Health monograph.) Washington, DC: Department of Health and Human Services, 1990. (DHHS No (ADM) 89-1631.)

6 Smith GR. Psychiatric consultation in somatization disorder. A randomised controlled study. $N$ Engl f Med 1986;314: $1407-13$

SIR,-Dr R P Arnold and colleagues' and others ${ }^{23}$ show that patients who have suffered sexual abuse in childhood may attempt suicide. But in our experience of patients with self poisoning, victims are reluctant to divulge histories of sexual abuse, as the following cases show.

Case 1-A 15 year old schoolgirl took 75 tablets of allopurinol $300 \mathrm{mg}$. On the third night after admission she confided in a woman house officer that she had been sexually abused by her mother's male cohabitee and by her own putative father.

Case 2-A 21 year old computer operator took 160 tablets of paracetamol $500 \mathrm{mg}$ and survived. He was grieving over the recent death of his grandmother and was worried about his own homosexuality. After several weeks of counselling he revealed to a social worker that, at the age of 14 , he had been seriously sexually assaulted by an older schoolboy.

Case 3-A 16 year old girl took 40 tablets of paracetamol $500 \mathrm{mg}$ with an unspecified amount of alcohol. Her mother told a senior registrar that her daughter had been raped two years previously. The patient subsequently admitted two vears of sexual and physical abuse by her father.

Case 4-A 21 year old woman was admitted having taken 12 tablets of carbamazepine $200 \mathrm{mg}$ and an unspecified amount of alcohol. She had cut both her wrists. A television producer who accompanied her explained that the patient was taking part in a programme on childhood sexual abuse because she had been abused by her father and his friends for several years until being taken into care at the age of 14 . The patient had a history of several episodes of self harm.

Case 5-A 15 year old schoolboy was admitted having taken 20 tablets of paracetamol $500 \mathrm{mg}$. One week earlier he had taken an overdose of paracetamol but had not been admitted to hospital. He divulged to the admission unit's social worker that he was bisexual and several weeks later told him that at the age of 9 he had been sexually assaulted by a 15 year old boy.

These cases show how reticent victims may be about sexual abuse: none of the patients reported a history of abuse when first admitted to hospital but did so only days or weeks after taking an overdose. Sympathetic listening by medical staff, nurses, and social workers may improve the detection of previous sexual abuse as a cause of overdose. Unsympathetic or punitive treatment might increase patients' feelings of unworthiness and reduce the chance of staff obtaining the relevant history. ${ }^{+}$

We are grateful to the house officers, nursing staff, and social workers who helped to care for these patients.

R E FERNER R J HASSALI D N BATEMAN M D RAWLINS

Wolfson Unit of Clinical Pharmacology,

Roval Victoria Infirmary,

Newcastle upon Tyne NE1 4LP

1 Arnold RP, Rogers D, Cook DAG. Medical problems of adults who were sexually abused in childhood. Br Med f 1990;300: 705-8. (17 March.)

2 Adams-Tucker C. Proximate effects of sexual abuse in childhood: a report on 28 children. Am f Psychiatry 1982;139:1252-6.

3 Garfinkel BD, Froese A, Hood J. Suicide attempts in children and adolescents. Am f Psychiatry 1982;139:1257-61.

4 Vizard $E$. Tranter $M$. The recognition of sexual abuse. In Bentovim A, Elton A, Hildebrand J, Tranter $M$, Vizard E, eds. Child sexual abuse within the family: assessment and treatment. London, Boston: Wright, 1988:60-9.

\section{Screening and the 1990 contract}

SIR, - In his necessarily brief mention of district health authority community health services Dr Simon Jenkins highlights the dangers of the trading environment envisaged by the white paper for the women using and the staff providing district health authority family planning clinics.

These clinics currently serve one third ${ }^{2}$ of the $3 \cdot 9$ million women ${ }^{2}$ who seek contraceptive advice and supplies from the NHS each year. If they are to be identified as areas of duplication and eliminated a cost effective preventive service that provides a clear public health benefit will be lost. In fact, examination of the services provided in district health authority clinics would show that they are complementary to, and not duplications of, general practitioners' services.

There is evidence that women seek different sources of contraceptive advice at different stages of their reproductive lives. Though there are individual exceptions, there is a trend for general practitioners to provide a service for women who are currently spacing pregnancies, whereas clinics provide for a larger proportion of women who are 